\title{
Glutamic Acid Decarboxylase (GAD) Immunocytochemistry of Developing Rabbit Hippocampus
}

\author{
Dennis D. Kunkel, ${ }^{\star}$ Anita E. Hendrickson, $\dagger$ Jang-Yen Wu, $\neq$ and Philip A. Schwartzkroin* $\S$ \\ *Department of Neurological Surgery, †Department of Biological Structure and Department of Ophthalmology, and \\ $\S$ Department of Physiology and Biophysics, University of Washington, School of Medicine, Seattle, Washington

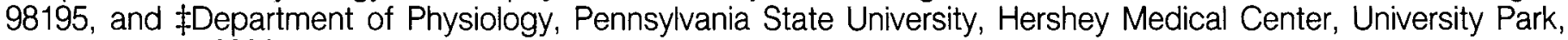 \\ Pennsylvania 16802
}

Immunocytochemical techniques were used to examine the synaptic relations of inhibitory interneurons in the developing rabbit hippocampus. Glutamic acid decarboxylase (GAD), the synthesizing enzyme for the inhibitory neurotransmitter GABA, was found in interneurons of immature $(8 \mathrm{~d}$ old $)$ as well as mature (30 d old) tissue. GAD-immunoreactivity was seen in somata, dendrites, and axon terminals of interneurons at both ages. Electron-microscopic examination revealed that GADpositive "terminals" in immature tissue were often not associated with the usual synaptic specializations, but were rather in simple apposition to the "postsynaptic" element. In mature tissue, GAD-positive terminals made symmetric contacts primarily with pyramidal cell somata, initial segments, and proximal dendrites. In addition, GAD-positive terminals synapsed onto both GAD-positive and GAD-negative interneuron profiles.

The neurotransmitter, GABA, is widely accepted as one of the primary inhibitory neurotransmitter substances in the mammalian forebrain. Its effects on pyramidal cells in the hippocampus have been carefully studied; here, GABA produces a hyperpolarization and conductance increase similar to the IPSP recorded in these pyramidal cells (Alger and Nicoll, 1982b; Andersen et al., 1980; Curtis et al., 1970). GABAergic effects are believed to be mediated by that cell type which has traditionally been associated with inhibition in hippocampus, the pyramidal basket cell (Andersen et al., 1964b; Lorente de No, 1934; Ramon y Cajal, 1911). GABA is released from interneuron terminals synapsing primarily on the cell body and initial segment regions of pyramidal neurons (Andersen et al., 1964a, b; Blackstad and Flood, 1963; Somogyi et al., 1983). The effectiveness of this interneuronal inhibitory GABAergic input is evidenced by the fact that excitatory input to pyramidal cells is rapidly curtailed in normal tissue; the IPSP that follows the EPSP is of considerable magnitude and duration (Kandel et al., 1961). Loss of interneurons (e.g., in epileptic brain), or blockade of GABAergic activity results in hyperexcitability of hippocampal tissue ( $\mathrm{Ri}$ bak et al., 1982; Schwartzkroin and Prince, 1980).

Although the GABAergic inhibitory activity is common in mature hippocampal tissue, it is relatively rare to see IPSPs in CA1 pyramidal cells of the immature rabbit hippocampus (Schwartzkroin, 1982). Ultrastructural investigation suggests that the "symmetric" synaptic profiles traditionally associated with

Received Apr. 5, 1985; revised Aug. 5, 1985; accepted Aug. 6, 1985.

This work was supported by grants from the NIH, NINCDS (NS 15317, NS 18895 ), and NSF (BNS 8209906). We would like to thank P. Schwartz for photographic assistance.

Correspondence should be addressed to Philip A. Schwartzkroin, Ph.D., Department of Neurological Surgery, University of Washington RI-20, Seattle, WA 98195.

Copyright (C) 1986 Society for Neuroscience 0270-6474/86/020541-12\$02.00/0 inhibitory function (Gottlieb and Cowan, 1972) are yet to be established (Schwartzkroin et al., 1982). This information is complemented by the finding that GABA, applied to the somatic membrane of immature CAl pyramidal cells, produces primarily depolarizing rather than hyperpolarizing responses (Mueller et al., 1984). It has been suggested (Alger and Nicoll, $1982 \mathrm{~b}$ ) that two distinct GABA receptors are found on pyramidal cells, and that the hyperpolarization-mediating receptor develops later, in parallel with innervation of tcrminals from inhibitory interneurons (Mueller et al., 1984). These physiological results are in contrast to the histological finding that the interneuron is present very early in development (Lorente de No, 1934). These cells can be seen in the newborn animal, at a time when IPSPs and symmetric synapses have not yet been identified in electrophysiological and ultrastructural investigations (Schwartzkroin and Kunkel, 1982). It is unclear, however, whether these immature interneuron cell types make synaptic contact with the pyramidal cells or whether they are capable of manufacturing and releasing GABA.

Immunocytochemical techniques have provided us with an opportunity to explore these questions. Immunoreactivity studies for the GABA-synthesizing enzyme, glutamic acid decarboxylase (GAD), have been carried out in a number of mammalian CNS structures including hippocampus (Frotscher et al., 1984; Hendrickson et al., 1983; Oertel et al., 1981; Ribak et al., 1981; Schmechel et al., 1984; Somogyi et al., 1983). Since our laboratory had previously characterized interneurons at the intracellular electrophysiological and ultrastructural levels (Schwartzkroin and Kunkel, 1985), we were interested in further defining the neurotransmitter status of these cells. By examining both mature and immature tissue for GAD-immunoreactivity, we hoped to shed some light on the question of whether the interneurons in the immature hippocampus were, in fact, GABAergic.

\section{Materials and Methods}

\section{Tissue preparation}

New Zealand white rabbits, ages 8 and $30 \mathrm{~d}$, were used for LM and EM immunocytochemical localization of GAD. Animals of these ages were chosen because our previous studies showed that inhibitory postsynaptic potentials (IPSPs) and symmetric (probably inhibitory) synapses were poorly developed in the CA1 region of $8 \mathrm{~d}$ old rabbits, but were virtually mature in the $30 \mathrm{~d}$ old rabbit (Schwartzkroin, 1982; Schwartzkroin et al., 1982). A total of six animals of each age were used. The rabbits were anesthesized with barbiturate and perfused intracardially with a solution of $3 \%$ paraformaldehyde in $0.1 \mathrm{~m}$ phosphate buffer $(\mathrm{PB} ; \mathrm{pH}$ 7.4) containing $0.34 \%$ L-lysine and $0.05 \%$ sodium $m$-periodate (Hendrickson et al., 1981). The brains were postfixed for $24-48 \mathrm{hr}$ in the same fixative at $4^{\circ} \mathrm{C}$, and the hippocampus removed. Tissue blocks for 

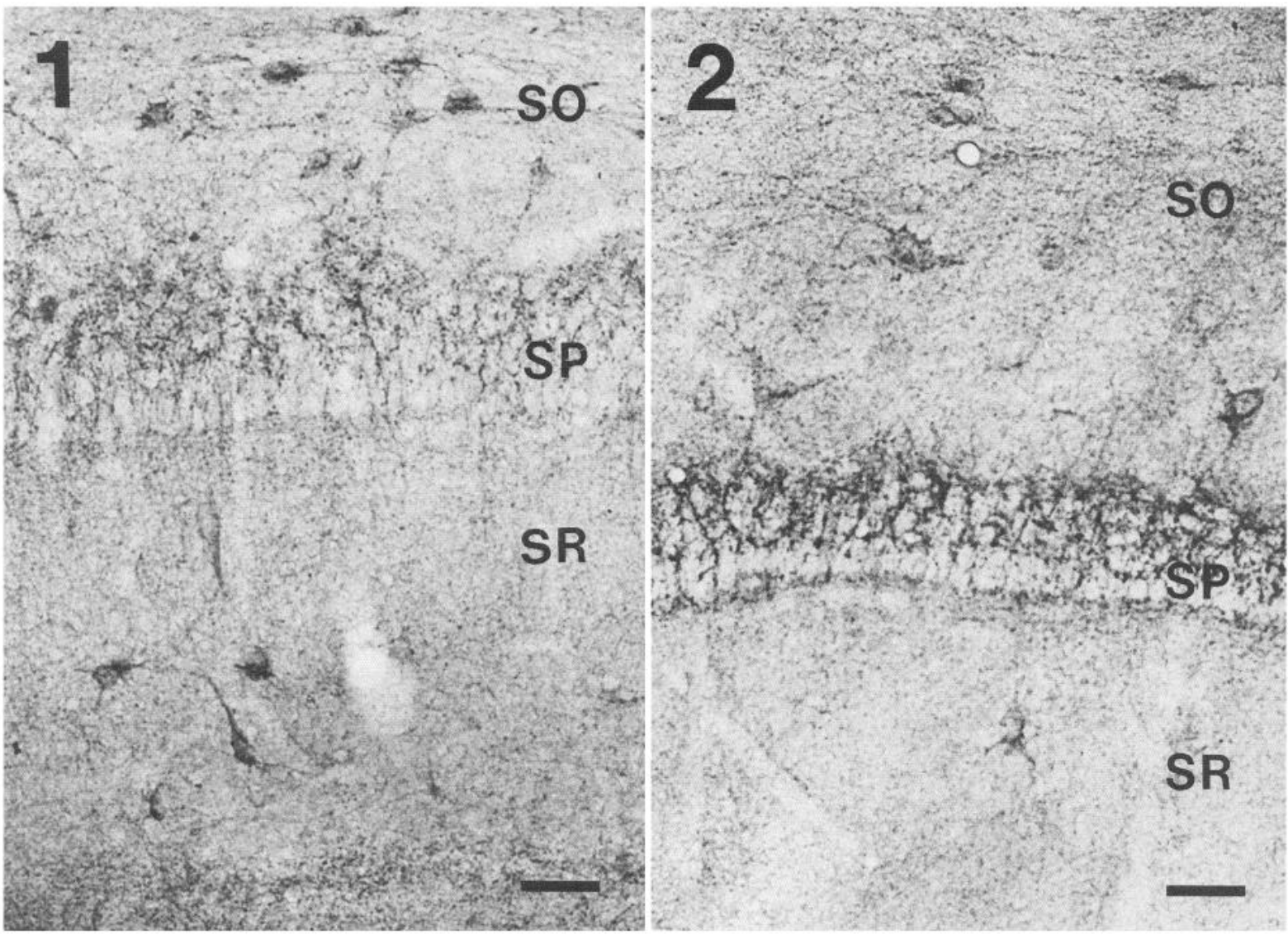

Figures 1 and 2. LM immunocytochemistry of glutamic acid decarboxylase (GAD) in CA1 laminae of rabbit hippocampus at postnatal ages $8 \mathrm{~d}$ (immature, $I$ ) and $30 \mathrm{~d}$ (mature, 2). GAD-positive neurons were primarily localized in stratum oriens ( $S O$ ). An immunoreactive band consisting of axonal processes and boutons was evident in stratum pyramidale $(S P)$ at both ages. This band was extremely dense in the mature hippocampus (2). $S R$, Radiatum. Scale bars, $50 \mu \mathrm{m}$.

LM were infiltrated with $30 \%$ sucrose in PB for $24 \mathrm{hr}$ at $4^{\circ} \mathrm{C}$, and transverse serial sections were cut at $30 \mu \mathrm{m}$ on a sliding microtome. Tissue blocks for EM were infiltrated with $10 \%$ sucrose in PB at $4^{\circ} \mathrm{C}$ for $24 \mathrm{hr}$. Transverse serial sections were cut at $70-100 \mu \mathrm{m}$ on a vibratome (Oxford Instruments).

\section{Antiserum}

GAD was purified to homogeneity from mouse brain, and the antiserum raised in rabbit (Wu et al., 1973, 1982). The specificity of anti-GAD serum has been established from a variety of immunochemical tests including immunodiffusion, immunoelectrophoresis, microcomplement fixation, enzyme inhibition, and immunoprecipitation (Saito et al., 1974; Wu, 1983; Wu et al., 1982). Numerous studies in various regions of the brain (e.g., Barber and Saito, 1976; Hendrickson et al., 1981; Houser et al., 1980; McLaughlin et al., 1974; Ribak et al., 1981; Somogyi et al., 1983, 1984; Wu et al., 1982) have been carried out with this antiserum. LM and EM immunocytochemical staining was based on the indirect peroxidase-antiperoxidase method (Sternberger, 1979).

\section{LM immunocytochemical procedure}

Prior to immunocytochemistry, sections from the $30 \mathrm{~d}$ animal were rinsed in $0.1 \mathrm{M}$ PB for $16-24 \mathrm{hr}$ and then pretreated in alcohol as follows: with $70 \% \mathrm{EtOH}$ for $5 \mathrm{~min}$; $100 \% \mathrm{MetOH}$ with $0.3 \% \mathrm{H}_{2} \mathrm{O}_{2}$ for $10 \mathrm{~min}$; $70 \% \mathrm{EtOH}$ for $5 \mathrm{~min}$; $0.1 \mathrm{M} \mathrm{PB}$ for $15 \mathrm{~min}$. All tissue sections were rinsed in $0.1 \mathrm{M}$ PBS for $1 \mathrm{hr}$ and then treated as follows (at room temperature, unless otherwise stated): incubated in primary GAD antiserum, diluted $1: 150$ in $0.05 \mathrm{M}$ PBS containing $1 \%$ normal goat serum and $0.35 \%$ Triton X-100 for $24-72 \mathrm{hr}$ at $4^{\circ} \mathrm{C}$ (PBS, $1 \%$ normal goat serum and $0.3 \%$ Triton X-100 was used to dilute all antisera); rinsed 1 $\mathrm{hr}$ in PBS containing $0.25 \%$ Triton X-100; incubated in goat antirabbit IgG diluted $1: 30$ for $45 \mathrm{~min}$ at $37^{\circ} \mathrm{C}$; rinsed $1 \mathrm{hr}$ in PBS containing
$0.25 \%$ Triton X-100; incubated in rabbit peroxidase-antiperoxidase (PAP), diluted $1: 100$ for $45 \mathrm{~min}$ at $37^{\circ} \mathrm{C}$; rinsed $30 \mathrm{~min}$ in PBS; rinsed $30 \mathrm{~min}$ in $0.1 \mathrm{M}$ Tris buffer (TB, pH 7.4); reacted with $0.04 \% 3,3^{\prime}$ diaminobenzidine tetrahydrochloride (DAB, Sigma) and $0.003 \% \mathrm{H}_{2} \mathrm{O}_{2}$ in TB for $8-15 \mathrm{~min}$; rinsed $15 \mathrm{~min}$ in TB; rinsed $15 \mathrm{~min}$ in PB. The sections were mounted on glass slides, dried, dehydrated, and coverslipped.

\section{EM immunocytochemical procedure}

Vibratomed sections were sunk in 30\% sucrose in PB for $24 \mathrm{hr}$ and frozen in liquid nitrogen. They were thawed at room temperature and rinsed as follows: $15 \%$ sucrose in PB for $15 \mathrm{~min}$; $0.1 \mathrm{M}$ PB for $15 \mathrm{~min}$; $0.1 \mathrm{~m}$ TB for $30 \mathrm{~min} ; 0.1 \mathrm{~m}$ TBS for $1 \mathrm{hr}$. The EM immunocytochemical procedure was as follows: Sections were incubated for $18-24 \mathrm{hr}$ in primary GAD antiserum, diluted 1:50 in PBS containing 1\% normal goat serum and either $0.04 \%$ Triton X-100 (for sections from $8 \mathrm{~d}$ animals) or $0.08 \%$ Triton X-100 (for sections from $30 \mathrm{~d}$ old animals); they were rinsed $2 \mathrm{hr}$ in TBS, incubated in goat antirabbit IgG (diluted 1:10) for $30 \mathrm{~min}$ at $37^{\circ} \mathrm{C}$, then for $2-5 \mathrm{hr}$ at room temperature; rinsed $2 \mathrm{hr}$ in TBS, incubated in rabbit PAP (diluted $1: 50$ ) for $30 \mathrm{~min}$ at $37^{\circ} \mathrm{C}$, then for $2 \mathrm{hr}$ at room temperature. They were rinsed $1 \mathrm{hr}$ in TBS, rinsed 1 $\mathrm{hr}$ in $0.1 \mathrm{M} \mathrm{TB}$, preincubated in $0.04 \% \mathrm{DAB}$ in TB for $15 \mathrm{~min}$, then reacted in DAB with $0.003 \% \mathrm{H}_{2} \mathrm{O}_{2}$ for $15 \mathrm{~min}$; they were then rinsed $15 \mathrm{~min}$ in TB, and finally rinsed $30 \mathrm{~min}$ in $0.1 \mathrm{~m}$ sodium cacodylate. Sections were postfixed with $2 \% \mathrm{OsO}_{4}$ in $0.1 \mathrm{~m}$ sodium cacodylate buffer for $45 \mathrm{~min}$, dehydrated and flat-embedded in Epon. Selected immunoreactive areas were photographed prior to reembedding. Serial ultrathin sections were cut, stained with uranyl acetate and lead citrate, and examined on a Philips 300 electron microscope.

Control sections were incubated, either substituting normal rabbit serum or no serum for the primary GAD antiserum. Control sections at the LM and EM levels showed only light background density. 

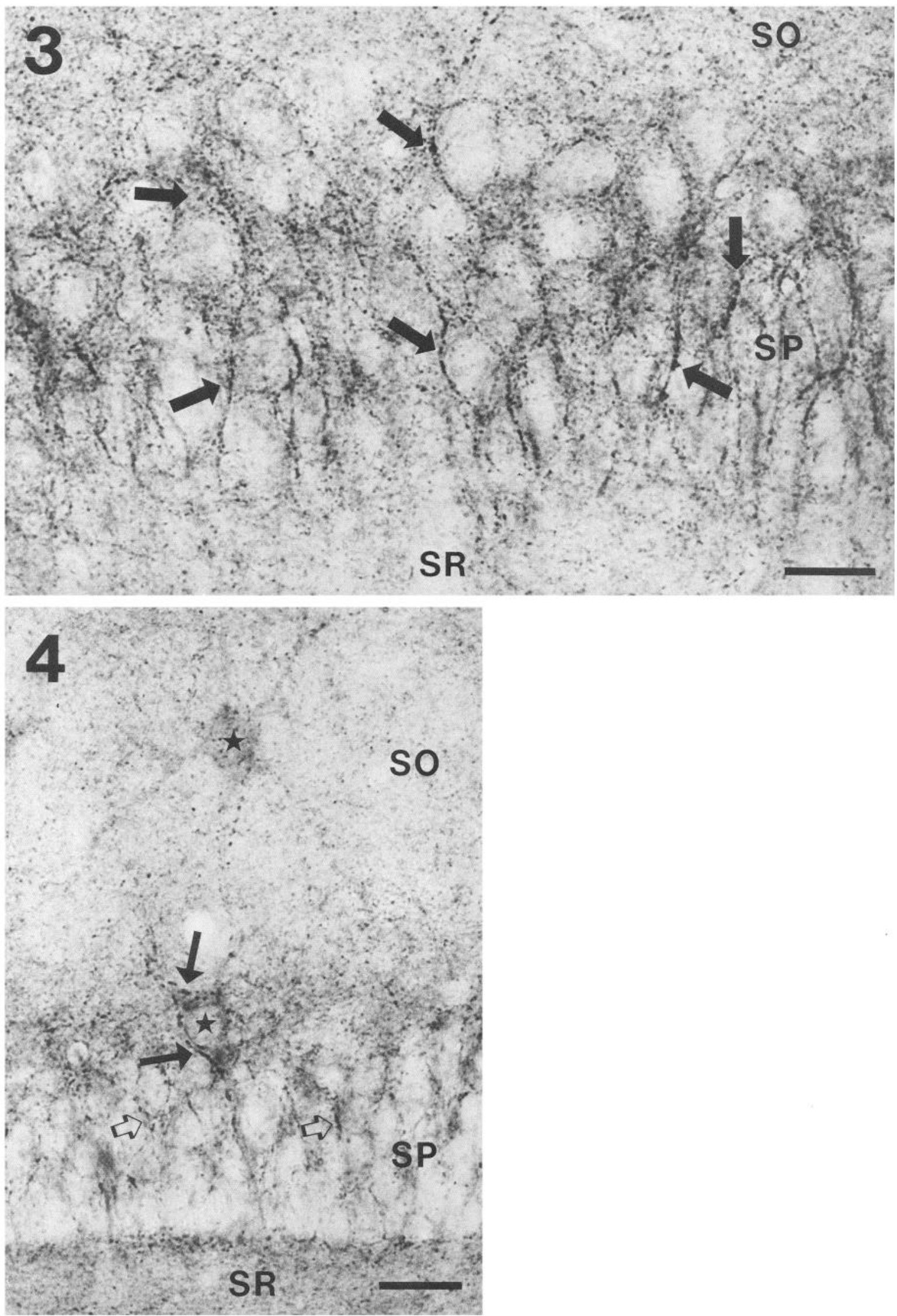

Figures 3 and 4. 3, Immunoreactive GAD axons and boutons (arrows) surrounding pyramidal somata in stratum pyramidale (SP) of a mature rabbit hippocampus. Some GAD-positive boutons were diffusely distributed in the proximal regions of strata oriens $(S O)$ and radiatum $(S R)$. Scale bar, $30 \mu \mathrm{m} .4$, Immunoreactive GAD neurons (stars) in stratum oriens $(S O)$ and at the oriens/pyramidale $(S P)$ border of a mature rabbit. GADpositive boutons were seen surrounding the GAD-positive neuron (solid arrows) as well as pyramidal cell somata (open arrows). Scale bar, $30 \mu \mathrm{m}$. 

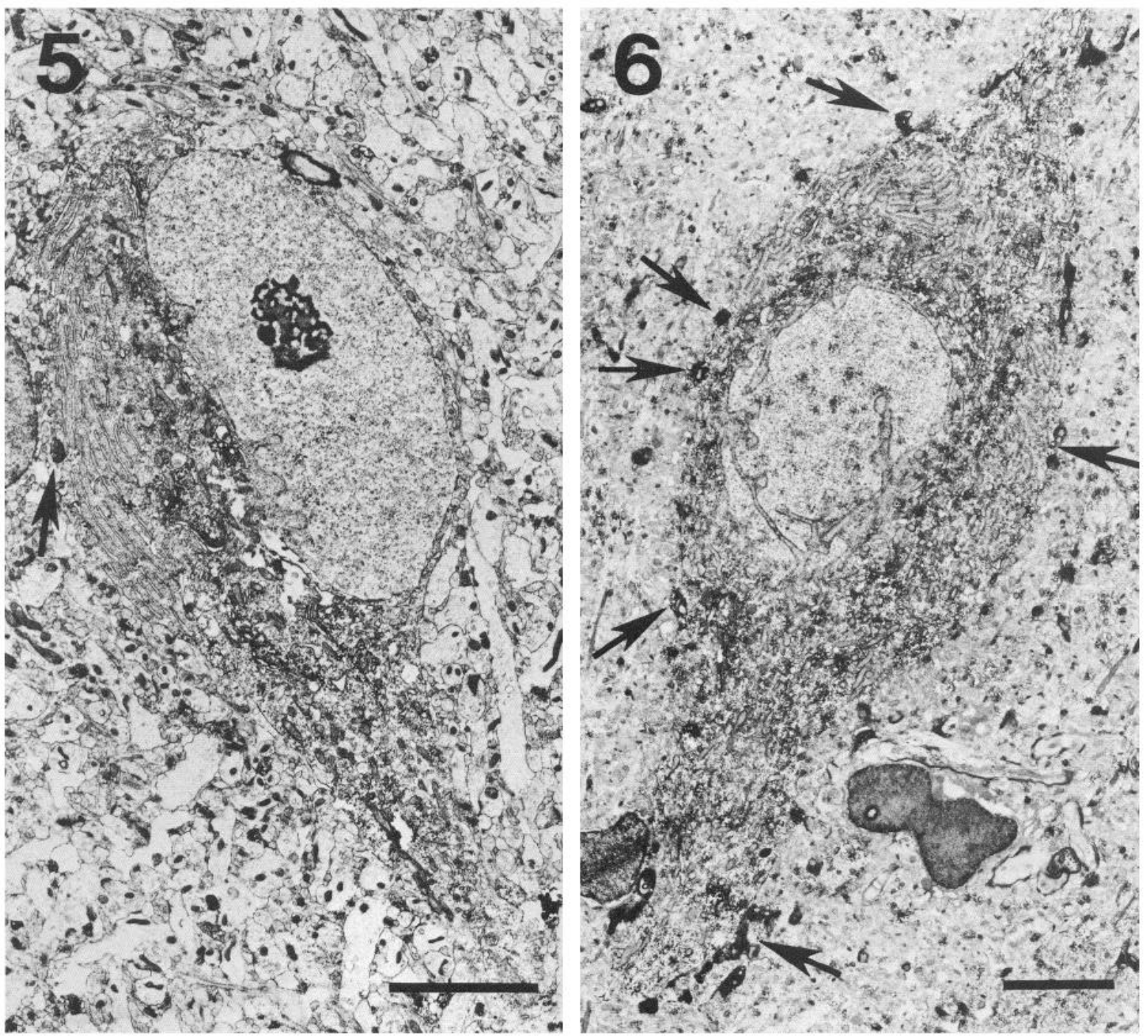

Figures 5 and 6. EMs of immunoreactive GAD neurons from stratum oriens in immature and mature rabbit hippocampus, respectively. These somata received synaptic input from GAD-positive boutons (arrows). Scale bars, $5.0 \mu \mathrm{m}$.

\section{Results}

\section{Light-microscopic observations}

\section{$G A D$ localization in somata}

Immunoreactive GAD neurons were present in three primary laminae of the CA1 region (strata oriens, pyramidale, and radiatum) in both immature ( $8 \mathrm{~d})$ and mature (30 d) rabbit hippocampus (Figs. 1 and 2). At both ages, GAD-positive somata were most numerous in stratum oriens. GAD-positive somata were generally ovoid to polygonal in shape $(25-35 \mu \mathrm{m}$ in diameter in immature rabbits; $30-45 \mu \mathrm{m}$ in diameter in mature rabbits). From their distribution and morphological features, these neurons correspond to the basket or "polygonal" neurons described by Lorente de No (1934) and Ramon y Cajal (1911). Some bipolar fusiform-shaped somata also were immunoreactive for GAD; these were primarily located in stratum oriens, near the alvear border. The extent of GAD-immunoreactivity in dendrites was variable and occurred mainly in major prox- imal dendrites, which extend primarily towards the hippocampal fissure ("apical") or the alveus ("basal").

\section{$G A D$ localization in axonal processes/boutons}

A dense GAD-immunoreactive band, consisting of an axonal plexus, was present in stratum pyramidale. The GAD immunoreactivity in this band, formed by pericellular punctae surrounding pyramidal cell somata (Figs. 2 and 3), was much denser in mature than in immature tissue. Subsequent electron microscopy revealed these punctae to be GAD-positive axonal varicosities and boutons (see below). The axonal plexus corresponds to the distribution of basket cell terminal boutons (Lorente de No, 1934). GAD-positive punctae were also evident in proximal strata oriens and radiatum (Figs. 3 and 4). This distribution was not as well localized or precise as the GAD reactivity in the pyramid cell layer. Finally, GAD-immunoreactive punctae were also found surrounding GAD-positive neurons in stratum oriens (Fig. 4).

Figures 7, 8, and 9. 7, Longitudinal section of an immunoreactive GAD dendrite from a $30 \mathrm{~d}$ old rabbit. Numerous asymmetric synapses (solid arrows) were seen contacting the dendrite. A large, GAD-positive profile (open arrow) also contacted the dendrite. Peroxidase reaction product is 

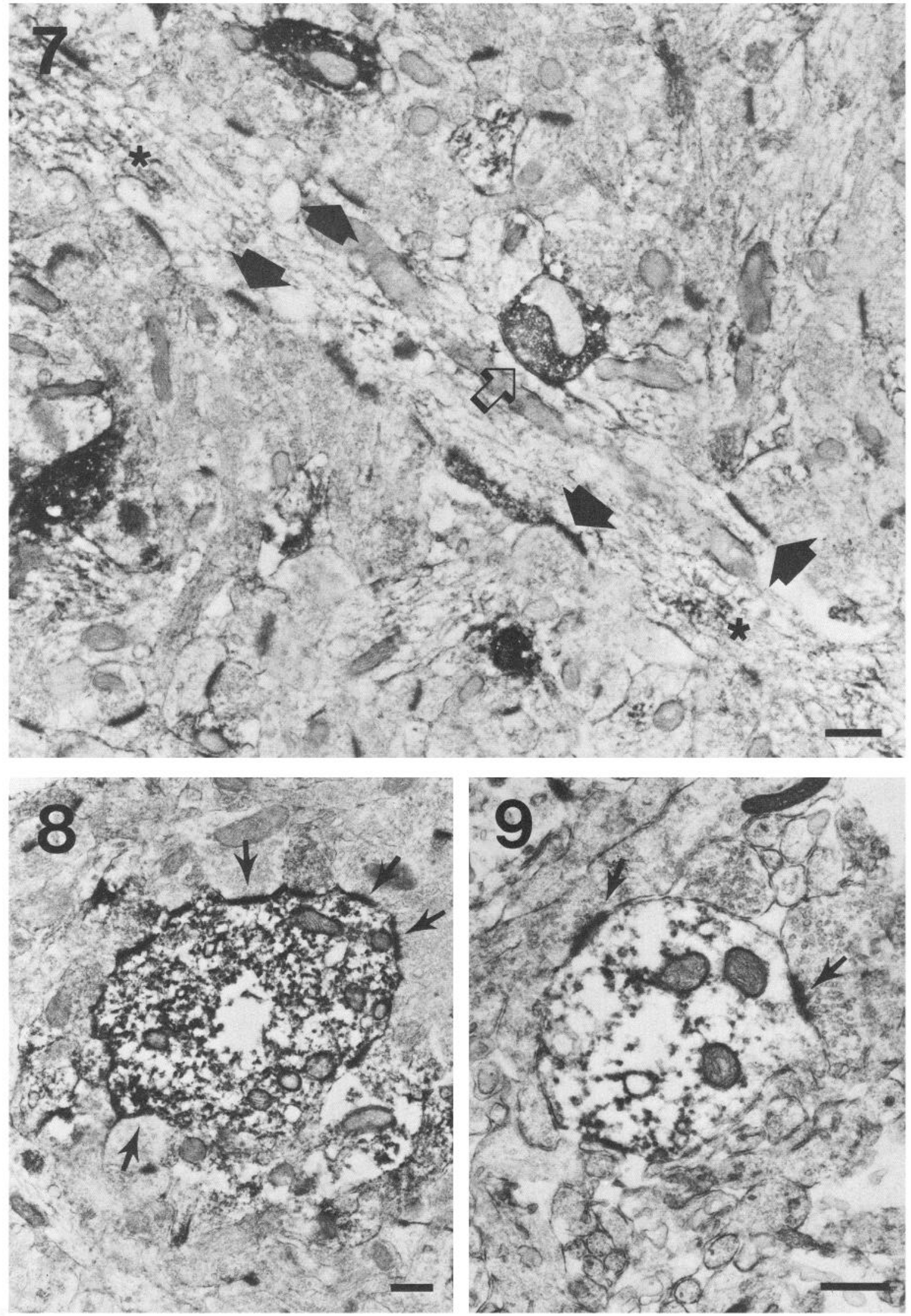

indicated by asterisks. Scale bar, $0.5 \mu \mathrm{m} .8$ and 9, Cross sections of GAD-positive dendrites in mature and immature (respectively) rabbit hippocampus. Note the extensive asymmetric synaptic input (arrows) onto the mature rabbit dendrite (Figure 8). Relatively few synaptic contacts (arrows) were evident on the immature dendrite (Figure 9). Scale bars, $0.5 \mu \mathrm{m}$. 


\section{Electron-microscopic observations}

\section{$G A D$ localization in somata}

GAD-immunoreactive somata were examined ultrastructurally in strata oriens and radiatum. GAD-positive somata were identified by the electron dense reaction product primarily localized in the peripheral cytoplasmic areas (Figs. 5 and 6). The reaction product appeared to be associated with various organelles, including the membrane surfaces of the Golgi complex cisternae, the endoplasmic reticulum, and the mitochondria. Distinguishing features of GAD somata include nuclei with convoluted nuclear envelopes (Fig. 6); relatively small nuclei compared to pyramidal somata (occupying $50-60 \%$ of the interneuron soma volume, compared to $80-95 \%$ for pyramidal cells); extensive granular endoplasmic reticulum and polyribosomes; and many mitochondria (see also Ribak and Anderson, 1980; Tömböl et al., 1979). GAD-positive neurons in immature rabbits had typically smaller soma size, a less convoluted nucleus, and fewer organelles than seen in the mature tissue (Fig. 5).

Immunoreactive GAD neurons were found to have GADpositive boutons on their surface membranes (Figs. 5 and 6). These boutons formed synaptic contacts with GAD-positive cells. GAD-positive somata in mature rabbits showed a much greater density of such GAD-positive synaptic profiles.

\section{$G A D$ localization in dendrites}

Immunoreactive GAD dendrites were commonly seen in strata oriens and radiatum (Fig. 7). The GAD reaction product was located on cytoplasmic membrane surfaces of mitochondria and smooth endoplasmic reticulum, and also appeared to be associated with microtubular arrays in many areas of the dendrite. Proximal GAD-positive dendrites were noticeably smaller in diameter than the nonreactive pyramidal cell dendrites $(2.0 \mathrm{vs}$ $4.0 \mu \mathrm{m})$. More distal GAD-positive dendritic processes were spindle-shaped or varicose, with many mitochondria and microtubules seen in the varicose regions. The GAD-positive dendrites were spineless and their shaft surfaces were covered with numerous synaptic contacts (Fig. 7), mainly of the asymmetric type (i.e., round vesicles in the presynaptic terminal and thick postsynaptic spccialization). In cross section, many synaptic profiles could be seen surrounding GAD-positive dendrites (Fig. 8). Immature dendrite morphology was less distinctive (i.e., less pronounced varicosities, few organelles) and synaptic input to the dendrite occurred at a considerably lower frequency (Fig. 9). Immunoreactive GAD-terminal profiles were also seen contacting GAD-positive dendrites (Fig. 7).

\section{$G A D$ localization in axonal processes/boutons}

Coinciding with LM observations, numerous immunoreactive GAD axonal processes and boutons were seen surrounding and contacting pyramidal somata in mature rabbits (Fig. 10). Significantly fewer GAD-positive profiles were present in immature rabbits (Fig. 11). It was often difficult to be sure of the precise synaptic relationship of immunoreactive terminals (i.e., membrane specialization and vesicle morphology) because of the dense reaction product in the terminal process or postsynaptic element. Comparisons of serially sectioned boutons in conventional EM material of hippocampus with immunoreactive terminals indicated that the GAD-positive elements made symmetric synaptic contacts (Figs. 12 and 13). GAD-positive terminal profiles were connected by thin cytoplasmic strands, thus forming the GAD-positive axonal plexus that is seen in stratum pyramidale (Figs. 3 and 10). Often a single GAD-positive profile could be found sandwiched between, and synapsing onto, two different pyramidal somata (Fig. 12).

GAD-positive axon profiles also contacted apical and basal dendrites (primary and secondary branches; Figs. 14, 15, and 16), with greater density of profiles seen on the proximal (as compared to distal) dendritic regions. The overall density of GAD-positive terminals on dendrites was lower than on pyramidal somata. Occasionally, GAD-positive profiles were seen contacting aspinous, nonimmunoreactive dendrites in strata oriens and radiatum (Fig. 18). These dendrites had numerous asymmetric contacts and were presumably dendrites from other interneurons. As indicated above, GAD-positive profiles were found contacting GAD-positive dendrites (Figs. 7 and 17) and somata (Figs. 5 and 6). Numerous GAD-positive synaptic profiles were also found in contact with pyramidal cell initial segments (Figs. 19 and 20). The initial segments were easily recognized by their multilayered membrane undercoating, fasciculated microtubules and cisternal organelles (Palay et al., 1968). In many EM fields, the majority of contacts onto initial segments appeared to be GAD-positive.

In comparing immature and mature tissue, GAD-immunoreactivity seemed less pronounced in immature rabbits. Somatic immunoreactivity was prominent (as in mature rabbits), but dendrite and axonal processes were not as well labeled. In immature rabbits, GAD-positive profiles were present on pyramidal somata, dendrites and initial segments, but these contacts were not well-developed synapses; specializations were poorly formed or absent (Figs. 11, 15, and 20). These contacts had few vesicles and an indistinct membrane density. This difference was especially apparent when immature and mature rabbit pyramidal cell initial segments were compared. The numerous GAD-positive synaptic contacts typical of the mature tissue (Fig. 19) contrasted with immature tissue, where GAD-positive profiles were apposed to, but apparently did not make synaptic contact with, the initial segment (Fig. 20). No synaptic specializations associated with initial segment synapses could be revealed in this immature tissue, even when terminals were serialsectioned.

\section{Discussion}

Our GAD-immunocytochemical studies of rabbit hippocampus have provided information on several points. First, we have confirmed that the GAD-positive cells labeled by this procedure are similar in location and shape to those "basket cells" previously identified as inhibitory interneurons on the basis of electrophysiology and conventional morphological examinations (Knowles and Schwartzkroin, 1981; Tömböl et al., 1979). Thus, it seems that the inhibitory interneurons identified in our previous studies (Schwartzkroin, 1982; Schwartzkroin and Kunkcl, 1982; Schwartzkroin et al., 1982) may indeed use GABA as a neurotransmitter. This observation does not, to be sure, imply that all interneurons in hippocampus are GABAergic, or that GABA-containing interneurons do not also manufacture other putative neurotransmitters. For example, recent immunocytochemical studies have demonstrated somatostatin and cholecystokinin (among other peptides) within interneuronal cell types in the CA1 region of hippocampus (Köhler and ChanPalay, 1982; Roberts et al., 1984; Somogyi et al., 1984). The physiological function of these peptides, however, remains unclear.

Second, it is clear that many other interneuronal cell types, quite distinct from the pyramidal basket cells upon which we initially focused, are immunoreactive for GAD; presumably, they also use GABA as a neurotransmitter. The functions of such cells are largely unknown, and there is little information available about their characteristics or roles in hippocampal local circuits. They vary widely in location, with some found in stratum oriens near the alvear border, and others scattered throughout stratum radiatum and stratum lacunosum/moleculare. Amaral (1978), using Golgi techniques, described a large number of different interneuron subtypes in the hilar region of the dentate gyrus. More recently, Somogyi et al. (1983) have suggested that at least two different subpopulations of GABA- 

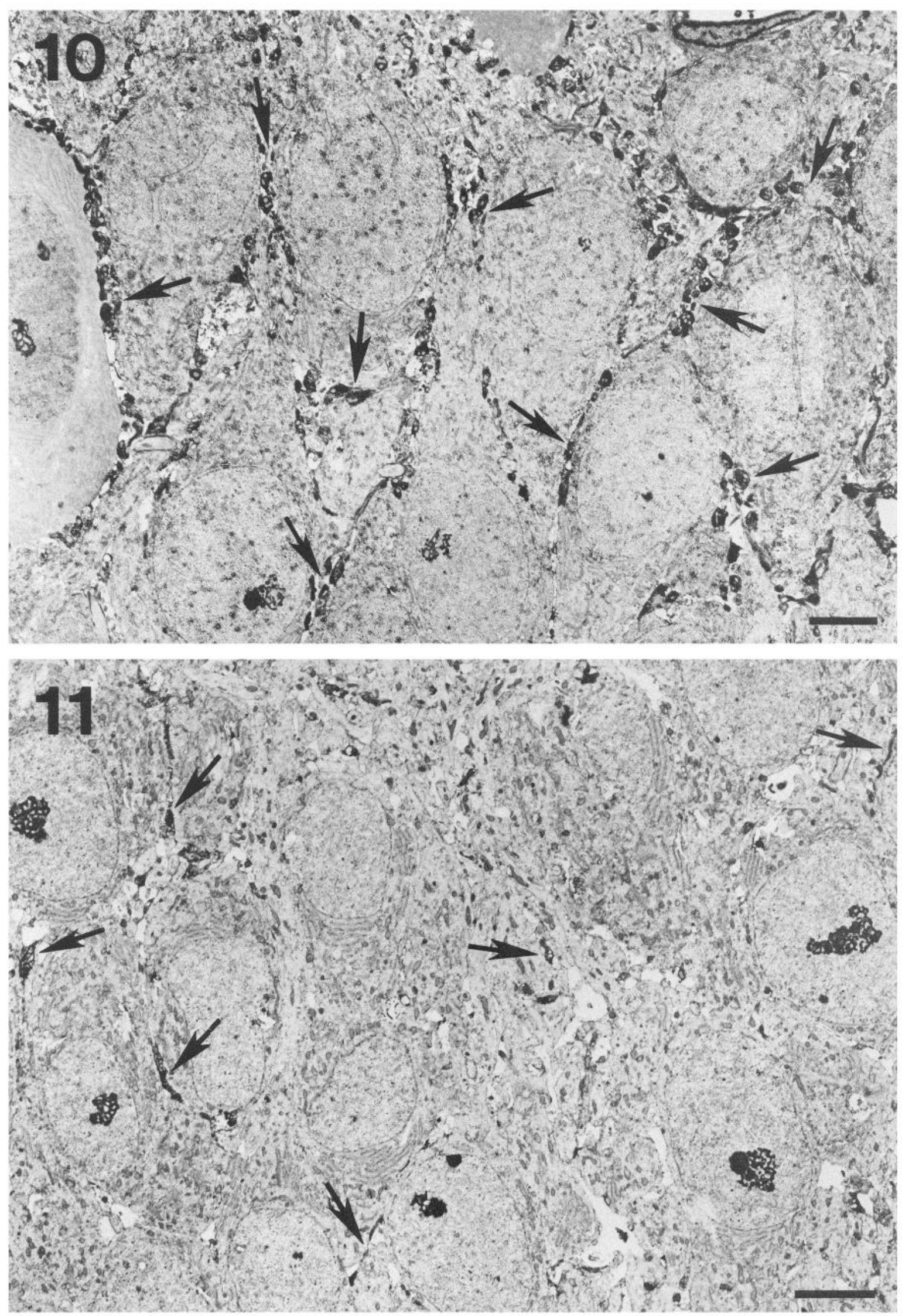

Figures 10 and 11. Low-magnification EMs of CA1 stratum pyramidale in mature and immature rabbit hippocampus. Note the dense distribution of GAD-positive axon profiles (arrows) surrounding pyramidal cell somata in the mature rabbit (Figure 10). Only a relatively few well-developed axonal terminals were seen in the immature rabbit (Figure 11). Scale bars, $5.0 \mu \mathrm{m}$. 

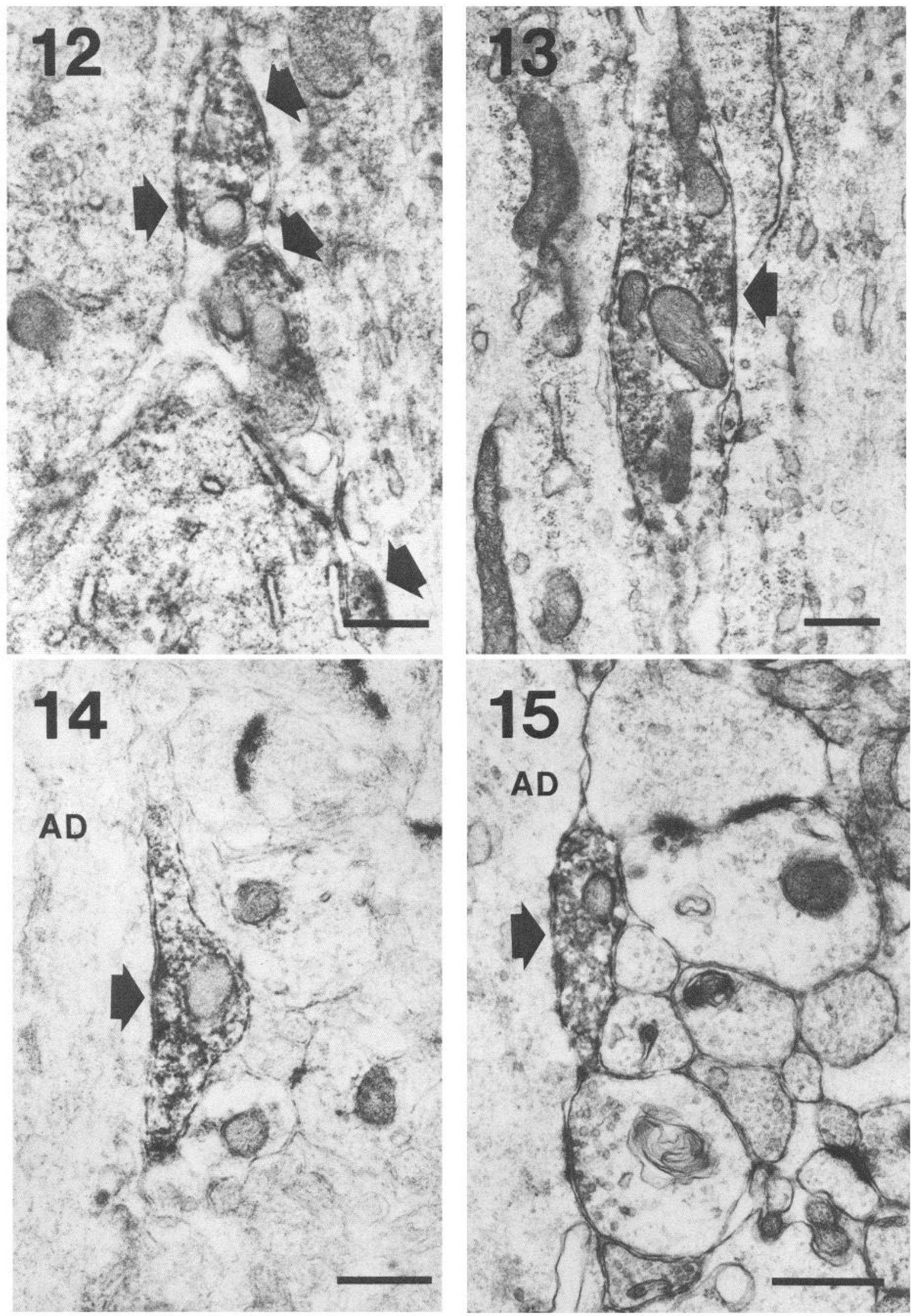

Figures 12, 13, 14, and 15. 12 and 13, Immunoreactive GAD axon profiles (arrows) forming synaptic contacts between pyramidal somata in mature (Figure 12) and immature (Figure 13) rabbit hippocampus. All serially-sectioned immunoreactive terminals made apparently symmetrical synaptic contacts. Scale bars, $0.5 \mu \mathrm{m}$. 14 and 15, Immunoreactive GAD axon profiles (arrows) contacting apical dendrites (AD) in mature (Figure 14) and immature (Figure 15) rabbit hippocampus. Scale bars, $0.5 \mu \mathrm{m}$. 

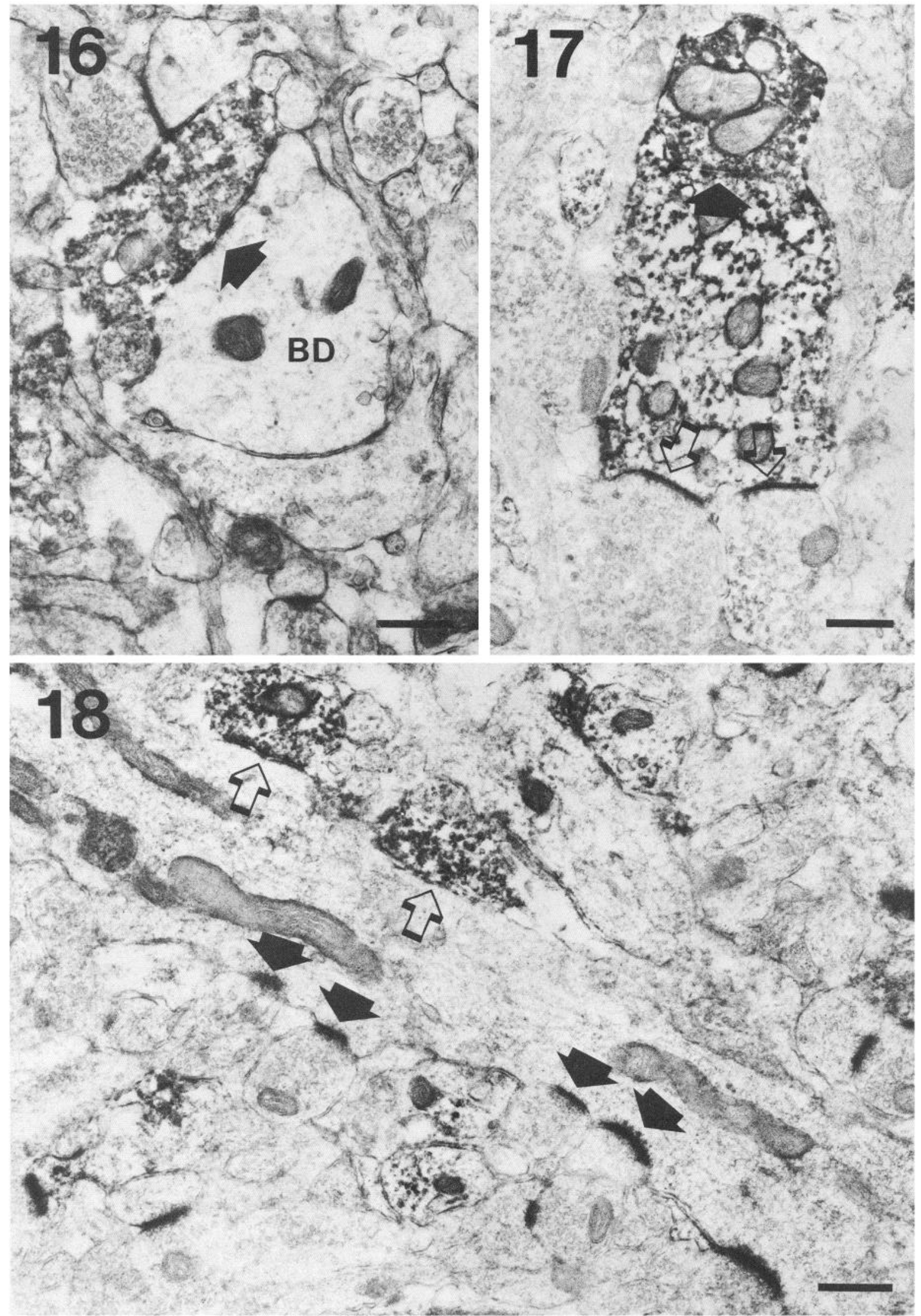

Figures 16, 17, and 18. 16, A GAD-positive axon profile (arrow) contacting a basal dendrite $(B D)$ in stratum oriens of mature hippocampus. Scale bar, $0.5 \mu \mathrm{m}$. 17, An immunoreactive GAD dendrite in stratum oriens of mature hippocampus receiving both GAD-positive (solid arrow) and GAD-negative (open arrows) synaptic contacts. Scale bar, $0.5 \mu \mathrm{m}$. 18, An aspinous, nonimmunoreactive interneuron dendrite, with numerous asymmetric synapses (solid arrows), which also receives GAD-positive contacts (open arrows). Scale bar, $0.5 \mu \mathrm{m}$. 

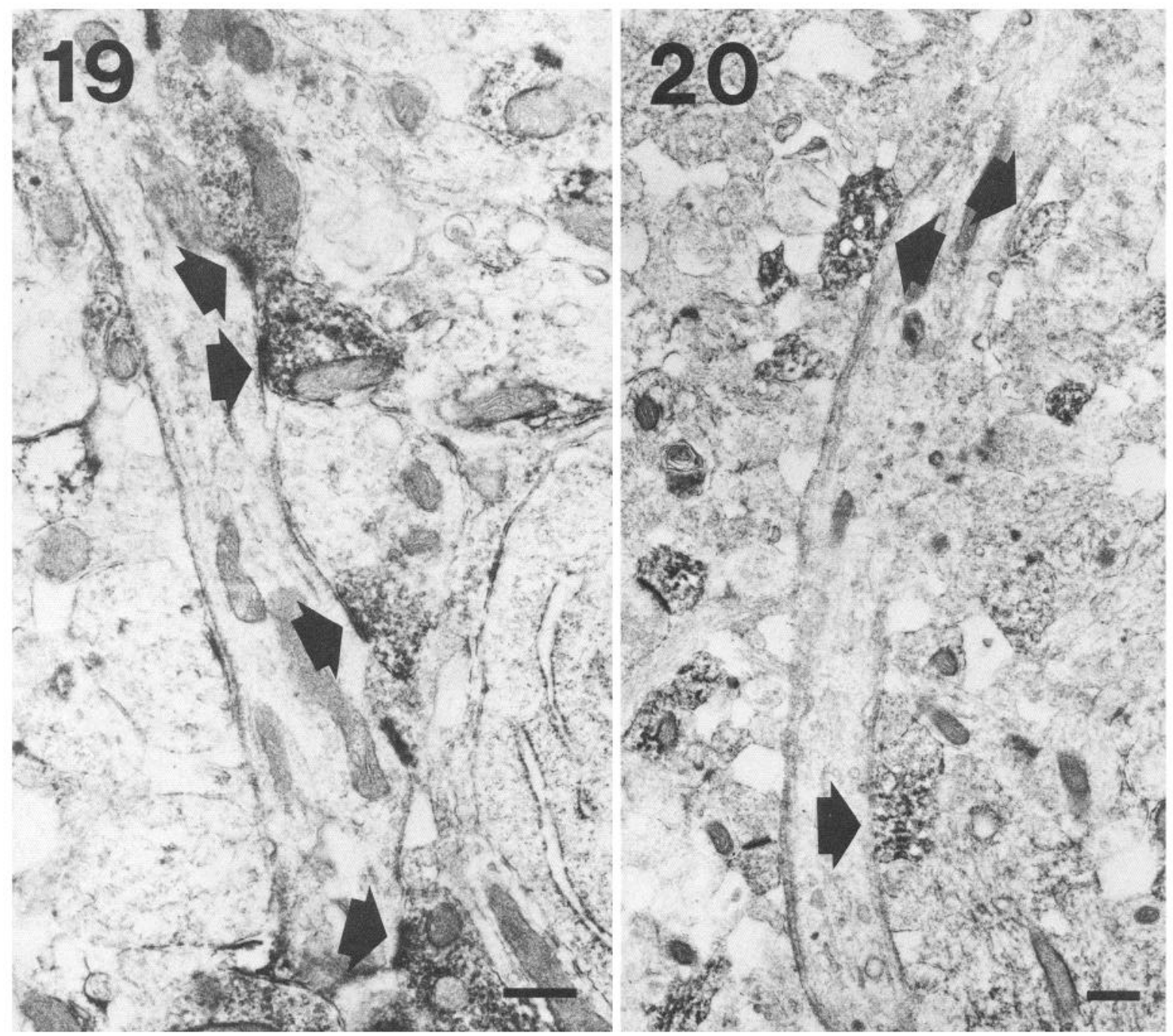

Figures 19 and 20. 19, Immunoreactive GAD terminal profiles (arrows) synapsing with a pyramidal cell initial segment in a mature rabbit hippocampus. The majority of contacts onto initial segments were GAD-positive. Scale bar, $0.5 \mu \mathrm{m}$. 20, Immunoreactive GAD terminal profiles (arrows) surrounding an initial segment from an immature pyramidal cell. Synaptic specializations associated with these GAD-positive boutons were not well developed in immature hippocampus. Scale bar, $0.5 \mu \mathrm{m}$.

ergic interneurons modulate pyramidal cell activity-one making exclusively axoaxonic contacts (on initial segments), and the other contributing axosomatic synapses. This diversity of interneuron type (and function) has been complicated by demonstrations that some cell types are immunoreactive for GAD and a peptide (Schmechel et al., 1984; Somogyi et al., 1984).

Third, our GAD-immunocytochemical studies show that there is significant GAD-immunoreactivity in the immature rabbit hippocampus. Interneuron cell types are clearly labeled, suggesting that the interneurons that are observed both morphologically and electrophysiologically in immature tissue do manufacture (and probably release) GABA. However, whereas GAD-positive terminals in mature tissue were normally associated with synaptic specializations (synaptic vesicles, pre- and postsynaptic densities), the GAD-positive fiber terminals in the immature tissue were not often associated with such specializations. Rather, apparent "terminals" of these immature GADpositive cells were found in simple apposition to postsynaptic membranes (presumably of pyramidal cells). This finding is consistent with the hypothesis developed in our previous studies (Mueller et al., 1984), which suggests that mature GABA actions develop in concert with the development of specific inhibitory synapses onto CA1 pyramidal cells.
A number of other interesting observations have been made in the course of this study. We have found a significant number of GAD-positive terminals in contact with initial segments of pyramidal cells. While this finding was not surprising, it was striking that the GABAergic terminals virtually surrounded the initial segment profiles (see also Somogyi et al., 1983). This observation supports the notion that inhibitory interneurons make strategically powerful synaptic contact with the major action-potential initiator of the pyramidal cells and therefore control pyramidal cell output. In addition, GAD-positive terminals were found in contact with apparent interneuron dendritic and somatic profiles, both GAD-positive and GAD-negative. Our identification of such postsynaptic elements as "interneuronal" is based on our previous characterization of physiologically identified and intracellularly labeled neurons (Schwartzkroin and Kunkel, 1985), as well as on interneuron descriptions by other investigators (Ribak and Anderson, 1980; Tömböl et al., 1979). Thus, there appears to be a significant interneuron projection to other interneurons within the hippocampal local circuit, as well as a direct afferent input to interneurons (Frotscher and Zimmer, 1983; Frotscher et al., 1984; Schwartzkroin and Kunkel, 1985). It should be noted, however, that some of the GAD-positive terminals may be from contra- 
laterally projecting GABAergic hilar neurons (Seress and Ribak, 1983). Still unclear is whether the GABAergic interneuronal projections are primarily to other GABAergic interneurons, to non-GABAergic interneurons, or to both. Our data clearly indicate the presence of a nonimmunoreactive interneuron subpopulation, which receives GABAergic input. However, no colchicine treatment was used in the present studies, leaving open the possibility that a significant proportion of GABAergic neurons were simply not labeled by the antiserum (Ribak et al., 1978). Nevertheless, given the present data, it is necessary to consider interactions of non-GABAergic interneurons in hippocampal local circuitry. For example, it has been shown recently that taurine also elicits a hyperpolarizing effect when it is applied iontophoretically or by perfusion to a rat hippocampal slice. Furthermore, the taurine-synthetic enzyme, cysteinesulfinic acid decarboxylase, has also been localized immunocytochemically in some interneurons in the rat hippocampus ( $\mathrm{Wu}$ et al., 1985).

Finally, it should be noted that while GAD-positive terminals onto pyramidal cells were primarily located on somala and initial segments, some GAD-positive profiles were found on the apical and basal dendrites of pyramidal cells. Recent studies have suggested that there is a dendritic inhibitory response generated in pyramidal cell dendrites (Alger and Nicoll, 1982a); however, the elements involved in mediating this component of the IPSP have not yet been identified. GABAergic input to pyramidal cell dendrites may be associated with either depolarizing or hyperpolarizing effects on the pyramidal cells (Andersen et al., 1980). In either case, the response appears to be associated with a large conductance increase, a phenomenon that might serve to effectively shunt other synaptic current. Such inhibitory synapses located on dendritic branches could "open up" the pyramidal cell dendritic tree, effectively producing dendritic processes of infinite length. This effect would serve to significantly alter the elcctrotonic structurc of that particular dendrite receiving the GABAergic input (Turner and Schwartzkroin, 1984) and presumably provide an effective mechanism for discretely modulating input to pyramidal cell dendrites.

To summarize: This immunocytochemical study of interneurons that use glutamic acid decarboxylasc to manufacturc GABA has shown that GABAergic interneurons are indeed present in the immature hippocampus, but that well-developed GABA synapses are lacking. In addition, GAD-immunocytochemistry has yielded a number of interesting observations regarding the synaptic patterns of GABAergic neurons. These observations, in turn, have generated new questions about the contacts and interactions of GABAergic interneurons within hippocampus.

\section{References}

Alger, B. E., and R. A. Nicoll (1982a) Feed-forward dendritic inhibition in rat hippocampal pyramidal cells studied in vitro. J. Physiol. (Lond.) 328: 105-123.

Alger, B. E., and R. A. Nicoll (1982b) Pharmacological evidence for two kinds of GABA receptor on rat hippocampal pyramidal cells studied in vitro. J. Physiol. (Lond.) 328: 125-141.

Amaral, D. G. (1978) A Golgi study of cell types in the hilar region of the hippocampus in the rat. J. Comp. Ncurol. 182: 851-914.

Andersen, P., R. Dingledine, L. Gjerstad, I. A. Langmoen, and A. Mosfeld-Laursen (1980) Two different responses of hippocampal pyramidal cells to application of gamma-amino butyric acid. J. Physiol. (Lond.) 305: 279-296.

Andersen, P., J. C. Eccles, and Y. Løyning (1964a) Location of postsynaptic inhibitory synapses of hippocampal pyramids. J. Neurophysiol. 27: 592-607.

Andersen, P., J. C. Eccles, and Y. Løyning (1964b) Pathway of postsynaptic inhibition in the hippocampus. J. Neurophysiol. 27: 608619.

Barber, R. P., and K. Saito (1976) Light microscopic visualization of GAD and GABA-T in immunocytochemical preparations of rodent
CNS. In GABA in Nervous System Function, T. N. Chase and D. B. Tower, eds., pp. 113-132, Raven, New York.

Blackstad, T. W., and P. R. Flood (1963) Ultrastructure of hippocampal axosomatic synapses. Nature 198: 542-543.

Curtis, D. R., D. Felix, and H. McLennan (1970) GABA and hippocampal inhibition. Br. J. Pharmacol. 40: 881-883.

Frotscher, M., and J. Zimmer (1983) Commissural fibers terminate on nonpyramidal neurons in the guinea pig hippocampus-a combined Golgi/EM degeneration study. Brain Res. 265: 289-293.

Frotscher, M., C. Leranth, K. Lubbers, and W. H. Oertel (1984) Commissural afferents innervate glutamate decarboxylase immunoreactive non-pyramidal neurons in the guinea pig hippocampus. Neurosci. Lett. 46: 137-143.

Gottlieb, D. I., and W. M. Cowan (1972) On the distribution of axonal terminals containing spheroidal and flattened synaptic vesicles in the hippocampus and dentate gyrus of the rat and cat. Z. Zellforsch. 129: 413-429.

Hendrickson, A. E., S. P. Hunt, and J.-Y. Wu (1981) Immunocytochemical localization of glutamic acid decarboxylase in monkey striate cortex. Nature 292: 605-607.

Hendrickson, A. E., M. P. Ogren, J. E. Vaughn, R. P. Barber, and J.Y. Wu (1983) Light and electron microscopic immunocytochemical localization of glutamic acid decarboxylase in monkey geniculate complex: Evidence for GABAergic neurons and synapses. J. Neurosci. 6: 1245-1262.

Houser, C. R., J. E. Vaughn, R. P. Barber, and E. Roberts (1980) GABA neurons are the major cell type of the nucleus reticularis thalami. Brain Res. 200: 341-354.

Kandel, E. R., W. A. Spencer, and F. J. Brinley, Jr. (1961) Electrophysiology of hippocampal neurons I. Sequential invasion and synaptic organization. J. Neurophysiol. 24: 225-242.

Knowles, W. D., and P. A. Schwartzkroin (1981) Local circuit synaptic interactions in hippocampal brain slices. J. Neurosci. 1: 318-322.

Köhler, C., and V. Chan-Palay (1982) Somatostatin-like immunoreactive neurons in the hippocampus: An immunocytochemical study in the rat. Neurosci. Lett. 34: 259-264.

Lorente de No, R. (1934) Studies on the structure of the cerebral cortex. II. Continuation of the study of the ammonic system. J. Psychol. Neurol. (Lpz.) 46: 113-177.

McLaughlin, B. J., J. G. Wood, K. Saito, R. Barber, J. E. Vaughn, E. Roberts, and J.-Y. Wu (1974) The fine structural localization of glutamate decarboxylase in synaptic terminals of rodent cerebellum. Brain Res. 76: 377-391.

Mueller, A. L., J. S. Taube, and P. A. Schwartzkroin (1984) Development of hyperpolarizing response to GABA in rabbit hippocampus in vitro. J. Neurosci. 4: 860-867.

Oertel, W. H., D. E. Schmechel, E. Mugnani, and I. J. Kopin (1981) Immunocytochemical localization of glutamate decarboxylase in rat cerebellum with a new antiserum. Neuroscience 6: 2715-2735.

Palay, S. L., A. Sotelo, A. Peters, and P. M. Orkand (1968) The axon hillock and the initial segment. J. Cell Biol. 38: 193-201.

Ramon y Cajal, S. (1911) Histologie du Systeme Nerveux de l'Homme et des Vertebres, Maloine, Paris.

Ribak, C. E., and Anderson, L. (1980) Ultrastructure of the pyramidal basket cells in the dentate gyrus of the rat. J. Comp. Neurol. 192: 903-916.

Ribak, C. E., R. M. Bradburne, and A. B. Harris (1982) A preferential loss of GABAergic symmetric synapses in epileptic foci: A quantitative ultrastructural analysis of monkey neocortex. J. Neurosci. 2: $1725-1735$.

Ribak, C. E., J. E. Vaughn, and R. P. Barber (1981) Immunocytochemical localization of GABAergic neurones at the electromicroscopical level. Histochem. J. 13: 555-582.

Ribak, C. E., J. E. Vaughn, and K. Saito (1978) Immunocytochemical localization of glutamic acid decarboxylase in neuronal somata following colchicine inhibition of axonal transport. Brain Res. 140: $315-$ 332.

Roberts, G. W., P. L. Woodhams, J. M. Polak, and T. J. Crow (1984) Distribution of neuropeptides in the limbic system of the rat: The hippocampus. Neuroscience 11:35-77.

Saito, K., J.-Y. Wu, T. Matsuda, and E. Roberts (1974) Immunocytochemical comparisons of vertebrate glutamic acid decarboxylase. Brain Res. 65: 277-285.

Schmechel, D. E., B. G. Vickrey, D. Fitzpatrick, and R. P. Elde (1984) GABAergic neurons of mammalian cerebral cortex; widespread subclass defined by somatostatin content. Neurosci. Lett. 47: 227-232. 
Schwartzkroin, P. A. (1982) Development of rabbit hippocampus: Physiology. Dev. Brain Res. 2: 469-486.

Schwartzkroin, P. A., and D. D. Kunkel (1982) Electrophysiology and morphology of the developing hippocampus of fetal rabbits. J. Neurosci. 2: 448-462.

Schwartzkroin, P. A., and D. D. Kunkel (1985) Morphology of identified interneurons in the CAl regions of guinea pig hippocampus. $\mathbf{J}$. Comp. Neurol. 232: 205-218.

Schwartzkroin, P. A., and D. A. Prince (1980) Changes in excitatory and inhibitory synaptic potentials leading to epileptogenic activity. Brain Res. 183: 61-76.

Schwartzkroin, P. A., D. D. Kunkel, and L. H. Mathers (1982) Development of rabbit hippocampus: Anatomy. Dev. Brain Res. 2: 453468.

Seress, L., and C. E. Ribak (1983) GABAergic cells in the dentate gyrus appear to be local circuit and projection neurons. Exp. Brain Res. 50: 173-182.

Somogyi, P., A. J. Hodgson, A. D. Smith, M. G. Nunzi, A. Gorio, and J.-Y. Wu (1984) Different populations of GABAergic neurons in the visual cortex and hippocampus of cat contain somatostatin - or cholecystokinin-immunoreactive material. J. Neurosci. 4: 2590-2603.

Somogyi, P., A. D. Smith, M. G. Nunzi, A. Gorio, H. Takagi, and J.Y. Wu (1983) Glutamate decarboxylase immunoreactivity in the hippocampus of the cat: Distribution of immunoreactive synaptic terminals with special reference to the axon initial segment of pyramidal neurons. J. Neurosci. 3: 1450-1468.
Sternberger, L. A. (1979) Immunocytochemistry, Wiley, New York Tömböl, T., M. Babosa, and P. Somogyi (1979) Interneurons: An electron microscopic study of the cat's hippocampal formation. II. Acta Morphologica Acad. Sci. Hung. 27: 297-313.

Turner, D. A., and P. A. Schwartzkroin (1984) Passive electrotonic structure and dendritic properties of hippocampal neurons. In Brain Slices, R. Dingledine, ed., pp. 25-50, Plenum, New York.

Wu, J.-Y. (1983) Preparation of glutamic acid decarboxylase as immunogen for immunocytochemistry. In Neuroimmunocytochemistry (IBRO Handbook Series: Methods in the Neurosciences), A. C. Cuello, ed., pp. 159-191, Wiley, Chichester, England.

Wu, J.-Y., C.-T. Lin, C. Brandon, T.-S. Chan, H. Mohler, and J. G. Richards (1982) Regulation and immunocytochemical characterization of glutamic acid decarboxylase. In Cytochemical Methods in Neuroanatomy, V. Chan-Palay and S. L. Palay, eds., pp. 279-296, A. R. Liss, New York.

Wu, J.-Y., T. Matsuda, and E. Roberts (1973) Purification and characterization of glutamic acid decarboxylase from mouse brain. J. Biol. Chem. 248: 3029-3034.

Wu, J.-Y., R. Thalmann, C.-T. Lin, and G.-X. Song (1985) Immunocytochemical and physiological identification of taurine neurons in mammalian CNS. In Taurine: Biological Actions and Clinical Perspectives, S. S. Oja, L. Ahtee, P. Kontro, and M. K. Paasonen, eds., pp. 261-270, A. R. Liss, New York. 